\title{
Poly(ADP-ribose)polymerase inhibition counteracts renal hypertrophy and multiple manifestations of peripheral neuropathy in diabetic Akita mice
}

\author{
VIKTOR R. DREL ${ }^{1}$, PAL PACHER ${ }^{2}$, ROMAN STAVNIICHUK ${ }^{1}$, WEIZHENG XU ${ }^{3}$, JIE ZHANG ${ }^{3}$, \\ TAMARA M. KUCHMEROVSKA ${ }^{4}$, BARBARA SLUSHER ${ }^{3}$ and IRINA G. OBROSOVA ${ }^{1}$

\begin{abstract}
${ }^{1}$ Pennington Biomedical Research Center, Louisiana State University System, Baton Rouge, LA; ${ }^{2}$ Section on Oxidative Stress Tissue Injury, Laboratory of Physiological Studies, NIH/NIAAA, Bethesda, MD; ${ }^{3}$ Eisai Inc., Baltimore, MD, USA; ${ }^{4}$ A.V. Palladin Institute of Biochemistry, Academy of Sciences of Ukraine, Kiev, Ukraine
\end{abstract}

Received April 4, 2011; Accepted May 9, 2011

DOI: $10.3892 / \mathrm{ijmm} .2011 .709$

\begin{abstract}
Poly(ADP-ribose) polymerase (PARP) activation has been implicated in the pathogenesis of diabetic complications, including nephropathy and peripheral neuropathy. This study aimed at evaluating the manifestations of both complications in diabetic Akita mice, a model of Type 1 (insulin-dependent) diabetes, and their amenability to treatment with the potent PARP inhibitor, 10-(4-methyl-piperazin-1-ylmethyl)-2H-7oxa-1,2-diaza-benzo[de] anthracen-3-one (GPI-15427). Male non-diabetic C57B16/J and diabetic C57Bl/6-Ins2Akita/J (Akita) mice were maintained with or without treatment with GPI-15427, $30 \mathrm{mg} / \mathrm{kg} / \mathrm{day}$, for 4 weeks starting from 16 weeks of age. Sixteen week-old Akita mice displayed sensory nerve conduction velocity (SNCV) deficit, whereas the motor nerve conduction velocity (MNCV) tended to decrease, but the difference with controls did not achieve statistical significance. They also developed thermal and mechanical hypoalgesia and tactile allodynia. SNCV deficit, mechanical hypoalgesia, and tactile allodynia progressed with age whereas the severity of thermal hypoalgesia was similar in 16- and 20-week-old Akita mice. PARP inhibition alleviated, although it did not completely reverse, SNCV deficit, thermal and mechanical hypoalgesia and tactile allodynia. Sixteen-week-old Akita mice displayed MNCV deficit $(41.3 \pm 2.5$ vs. $51.0 \pm 1.2 \mathrm{~m} / \mathrm{sec}$ in non-diabetic controls, $\mathrm{P}<0.01$ ), axonal atrophy of myelinated fibers, kidney hypertrophy, and albuminuria. MNCV slowing, axonal atrophy, and kidney hypertrophy, but not albuminuria, were less severe in GPI-15427-treated age-matched Akita mice. Neuroprotective
\end{abstract}

Correspondence to: Dr Irina G. Obrosova, Pennington Biomedical Research Center, Louisiana State University System, 6400 Perkins Road, Baton Rouge, LA 70808, USA

E-mail: obrosoig@pbrc.edu

Key words: albuminuria, diabetic Akita mouse, peripheral diabetic neuropathy, poly(ADP-ribose) polymerase, p38 mitogen-activated protein kinase, renal hypertrophy and nephroprotective effects of PARP inhibition were not due to alleviation of diabetic hyperglycemia, or peripheral nerve p38 mitogen-activated protein kinase activation. GPI-15427 did not affect any variables in control mice. In conclusion, the findings support an important role for PARP activation in diabetic peripheral neuropathy and kidney hypertrophy associated with Type 1 diabetes, and provide rationale for development and further studies of PARP inhibitors, for the prevention and treatment of these complications.

\section{Introduction}

Diabetic peripheral neuropathy (DPN) and nephropathy (DN) are among the most devastating complications of diabetes mellitus which lead to foot amputation (1) and kidney failure (2). With the exception of the aldose reductase inhibitor epalrestat in Japan (3), and $\alpha$-lipoic acid in several countries (4), no pathogenetic treatment for DPN is currently available. Several aldose reductase inhibitors, the protein kinase $\mathrm{C}$ inhibitor ruboxistaurin, acetyl carnitine, and the nerve growth factor showed only modest efficacy in clinical trials, or have been abandoned due to adverse side effects. The only treatment options for DN include angiotensin-converting enzyme inhibitors and angiotensin II receptor blockers which often have a limited efficacy.

Evidence for the important role of poly(ADP-ribose) polymerase (PARP), the enzyme converting NAD to nicotinamide and (ADP-ribose) residues, which attach to nuclear proteins and each other with the formation of poly(ADP-ribose) polymer, in diabetic complications is emerging (5-8). In particular, PARP activation has been implicated in motor (MNCV) and sensory (SNCV) nerve conduction velocity deficits, neurovascular dysfunction, sensory disorders, such as thermal and mechanical hyper- and hypoalgesia and tactile allodynia, small sensory nerve fiber degeneration, and axonal atrophy of large myelinated fibers, characteristic for DPN (9-12). PARP has also been demonstrated to play an important role in albuminuria, mesangial expansion, and podocyte loss associated with DN (13-16). Note, that all experimental studies of the role for PARP in complications of Type 1 (insulin-dependent) diabetes, the 
most debilitating form of diabetes mellitus, have been performed in rats and mice in which diabetes was induced by streptozotocin (STZ) treatment (5-11, 14-16).

Recent, quite successful, clinical trials identified the PARP inhibitor olaparib as a potential treatment option for different types of malignant tumors (17-19). FDA approval of this agent as a new cancer therapy would undoubtedly expedite clinical trials of PARP inhibitors in other pathological conditions, including diabetes mellitus. A proof-of-efficacy in animal models of DPN and DN other than STZ-diabetic rats and mice would provide a better justification for long-term and expensive trials of PARP inhibitors in both complications. We, therefore, studied manifestations of DPN and evaluated the PARP inhibitor 10-(4-methyl-piperazin-1-ylmethyl)-2H-7-oxa-1,2-diazabenzo[de] an-thracen-3-one (GPI-15427, Eisai Inc.) in diabetic C57Bl/6-Ins2Akita/J (Akita) mice, a model of Type 1 diabetes (20). We also assessed the effect of PARP inhibition on kidney hypertrophy and albuminuria although it has been demonstrated that the Akita mouse, at least the one on the C57Bl6/J background, is not a robust animal model of Type $1 \mathrm{DN}$ (21).

\section{Materials and methods}

Reagents. Unless otherwise stated, all chemicals were of reagent-grade quality, and were purchased from Sigma Chemical Co., St. Louis, MO. GPI-15427 was obtained from Eisai, Inc., Baltimore, MD. The rabbit polyclonal antibody to total p38 MAPK was obtained from Santa Cruz Biotechnology (Santa Cruz, CA) and the rabbit polyclonal antibody to phosphorylated p38 MAPK from Cell Signaling (Danvers, MA). Reagents for immunohistochemistry were purchased from Dako Laboratories, Inc., Santa Barbara, CA.

Animals. The experiments were performed in accordance with regulations specified by the Guide for the Care and Handling of Laboratory Animals (NIH Publication no. 85-23) and the Pennington Biomedical Research Center Protocol for Animal Studies. Five 6-week-old male C57B16/J and diabetic Akita mice were purchased from Jackson Laboratories. All the mice were fed standard mouse chow (PMI Nutrition International, Brentwood, MO) and had ad libitum access to water. Starting from 16 weeks of age, control and Akita mice were maintained with or without treatment with GPI- $15427,30 \mathrm{mg} / \mathrm{kg} / \mathrm{day}$, for 4 weeks. Diabetes was confirmed in Akita mice by glucose measurements in non-fasting blood samples taken from the tail vein one day before initiation of GP-15427 treatment and the day before the animals were sacrificed. Physiological and behavioral measurements were obtained before and after GPI-15427 treatment. MNCV and SNCV were measured in mice anaesthetized with a mixture of ketamine and xylazine ( $45 \mathrm{mg} / \mathrm{kg}$ and $15 \mathrm{mg} / \mathrm{kg}$ body weight, respectively, i.p.). At the end of the study, mice were placed in individual metabolic cages (Lab Products, Inc., Seaford, DE) and urine was collected for $48 \mathrm{~h}$. Urine specimens were centrifuged at $12,000 \mathrm{x} \mathrm{g}$ $\left(4^{\circ} \mathrm{C}, 10 \mathrm{~min}\right)$ and frozen for subsequent assessment of albumin by ELISA.

Anesthesia, euthanasia and tissue sampling. The animals were sedated by $\mathrm{CO}_{2}$, and immediately sacrificed by cervical dislocation. The kidneys were dissected, cleaned from the surrounding fat tissue, and weighed. Sciatic nerves were rapidly dissected and frozen in liquid nitrogen for subsequent assessment of total and phosphorylated p38 mitogen-activated protein kinase (MAPK). Tibial nerves were fixed (see below) and later used for assessment of myelinated fiber diameter and myelinated fiber diameter distribution.

Urinary albumin excretion. Urinary albumin was assessed by ELISA (AssayMax mouse albumin ELISA kit, Assaypro, St. Charles, MO) according to the manufacturer's instructions.

Physiology and behavioral tests. Sciatic MNCV, hind-limb digital SNCV, thermal algesia (plantar test by the Hargreaves method), mechanical algesia (tail-pressure Randall-Selitto test), and tactile response thresholds (flexible von Frey filament test) were measured as previously described $(9,22,23)$.

Western blot analysis of total and phosphorylated p38 MAPK. Sciatic nerve materials $(\sim 10-20 \mathrm{mg})$ were placed on ice in $200 \mu \mathrm{l}$ of RIPA buffer containing $50 \mathrm{mmol} / \mathrm{l}$ Tris-HCl, pH 7.2; $150 \mathrm{mmol} / \mathrm{l} \mathrm{NaCl} ; 0.1 \%$ sodium dodecyl sulfate; $1 \% \mathrm{NP}-40$; $5 \mathrm{mmol} / \mathrm{l} \mathrm{EDTA;} 1 \mathrm{mmol} / \mathrm{l}$ EGTA; $1 \%$ sodium deoxycholate and the protease/phosphatase inhibitors leupeptin $(10 \mu \mathrm{g} / \mathrm{ml})$, pepstatin $(1 \mu \mathrm{g} / \mathrm{ml})$, aprotinin $(20 \mu \mathrm{g} / \mathrm{ml})$, benzamidine $(10 \mathrm{mM})$, phenylmethylsulfonyl fluoride (1 mM), sodium orthovanadate $(1 \mathrm{mmol} / \mathrm{l})$, and homogenized on ice. The homogenates were sonicated (4 times for $10 \mathrm{sec}$ ) and centrifuged at $14,000 \mathrm{x} \mathrm{g}$ for $20 \mathrm{~min}$. All the afore-mentioned steps were performed at $4^{\circ} \mathrm{C}$. The lysates ( $20 \mu \mathrm{g}$ protein) were mixed with equal volumes of $2 \mathrm{X}$ sample-loading buffer containing $62.5 \mathrm{mmol} / \mathrm{l}$ Tris- $\mathrm{HCl}$, $\mathrm{pH} 6.8 ; 2 \%$ sodium dodecyl sulfate; $5 \% \beta$-mercaptoethanol; $10 \%$ glycerol and $0.025 \%$ bromophenol blue, and fractionated in 10\% SDS-PAGE in an electrophoresis cell (Mini-Protean III; Bio-Rad Laboratories, Richmond, CA). Electrophoresis was conducted at $15 \mathrm{~mA}$ constant current for stacking, and at $25 \mathrm{~mA}$ for protein separation. Gel contents were electrotransferred at $80 \mathrm{~V}$ for $2 \mathrm{~h}$ to nitrocellulose membranes using the Mini Trans-Blot cell (Bio-Rad Laboratories) and Western transfer buffer [25 mmol/l Tris-HCl, pH 8.3; $192 \mathrm{mmol} / 1$ glycine; and $20 \%(\mathrm{v} / \mathrm{v})$ methanol]. Free binding sites were blocked in $5 \%$ (w/v) BSA in $20 \mathrm{mmol} / \mathrm{l}$ Tris- $\mathrm{HCl}$ buffer, $\mathrm{pH}$ 7.5, containing $150 \mathrm{mmol} / 1 \mathrm{NaCl}$ and $0.05 \%$ Tween-20, for $1 \mathrm{~h}$, after which the corresponding primary antibodies were applied overnight. The horseradish peroxidase-conjugated secondary antibodies were then applied for $1 \mathrm{~h}$. In the Western blot analysis of phosphorylated p38 MAPK, the signal enhancer HIKARI (Nacalai USA, San Diego, CA) was applied with both primary and secondary antibodies according to the manufacturer's instructions. After extensive washing, protein bands detected by the antibodies were visualized with the Amersham ECL ${ }^{\mathrm{TM}}$ Western Blotting Detection Reagent (Little Chalfont, Buckinghamshire, UK). Membranes were then stripped in $25 \mathrm{mmol} / \mathrm{l}$ glycine- $\mathrm{HCl}$, $\mathrm{pH} 2.5$ buffer containing $2 \%$ SDS, and reprobed with $\beta$-actin antibody to confirm equal protein loading.

Tibial nerve morphometry. Tibial nerve morphometry was performed as previously described $(24,25)$. Tibial nerves were fixed overnight at $4^{\circ} \mathrm{C}$ in $2.5 \%$ glutaraldehyde buffered with $0.05 \mathrm{mmol} / \mathrm{l}$ sodium cacodylate $(\mathrm{pH}$ 7.3). The fixed samples were post-fixed in $1 \%$ osmium tetroxide and dehydrated through 
Table I. Body weights and blood glucose concentrations in non-diabetic and diabetic Akita mice maintained with or without GPI-15427 treatment.

\begin{tabular}{|c|c|c|c|c|}
\hline Variables & Control & Control + GPI & Akita & Akita + GPI \\
\hline \multicolumn{5}{|l|}{ 16-week time point (prior to treatment) } \\
\hline Body weight, g & $28.9 \pm 0.7$ & & $23.8 \pm 0.6^{\mathrm{a}}$ & \\
\hline Non-fasting blood glucose, $\mathrm{mmol} / \mathrm{l}$ & $10.9 \pm 0.4$ & & $>33.3$ & \\
\hline Fasting blood glucose, mmol/1 & $6.4 \pm 0.5$ & & $24.7 \pm 1.2^{\mathrm{a}}$ & \\
\hline \multicolumn{5}{|l|}{ 20-week time point (final measurements) } \\
\hline Body weight, g & $31.2 \pm 0.8$ & $30.8 \pm 0.8$ & $24.3 \pm 0.6^{\mathrm{a}}$ & $24.1 \pm 0.7^{\mathrm{a}}$ \\
\hline Non-fasting blood glucose, $\mathrm{mmol} / \mathrm{l}$ & $10.4 \pm 0.5$ & $9.9 \pm 0.5$ & $>33.3$ & $>33.3$ \\
\hline Fasting blood glucose, mmol/l & $6.9 \pm 0.5$ & $7 \pm 0.6$ & $25.7 \pm 1.4^{\mathrm{a}}$ & $25.3 \pm 1.6^{\mathrm{a}}$ \\
\hline
\end{tabular}

Data are expressed as mean $\pm \mathrm{SEM}, \mathrm{n}=10$ /group. ${ }^{\mathrm{a}} \mathrm{P}<0.01$ vs. non-diabetic controls; GPI, GPI-15427.

Table II. Motor and sensory nerve conduction velocities in non-diabetic and diabetic Akita mice maintained with or without GPI-15427 treatment.

\begin{tabular}{lccc}
\hline Variables & Control & Control + GPI & Akita \\
\hline 16-week time point (prior to treatment) & & & $45.4 \pm 1.8$ \\
MNCV, m/sec & $48.2 \pm 1.8$ & $30.2 \pm 0.8^{\mathrm{a}}$ \\
SNCV, m/sec & $37.5 \pm 0.8$ & & \\
20-week time point (final measurements) & & & $41.3 \pm 2.6^{\mathrm{a}}$ \\
MNCV, m/sec & $51.8 \pm 1.2$ & $51 \pm 2$ & $48.9 \pm 1.6^{\mathrm{b}}$ \\
SNCV, m/sec & $36.9 \pm 0.4$ & $37.3 \pm 0.9$ & $29.9 \pm 0.7^{\mathrm{a}}$ \\
\hline
\end{tabular}

Data are expressed as mean \pm SEM, $n=8$-10/group. MNCV, motor nerve conduction velocity; SNCV, sensory nerve conduction velocity; ${ }^{\mathrm{a}} \mathrm{P}<0.01$ vs. non-diabetic controls; ${ }^{b} \mathrm{P}<0.01$ vs. untreated diabetic Akita mice. GPI, GPI-15427.

an ascending series of ethanol concentrations. Fixed nerves were embedded in epon and polymerized. Semi-thin $(1 \mu \mathrm{m})$ transverse nerve sections were stained with toluidine blue. Myelinated nerve fiber diameter was measured at a magnification of x1600 by a computer-assisted image analyzing system (NIH Image, Agfa Arcus scanner connecting with Macintosh Quadra 700, Cupertino, CA) as described. For evaluation of myelinated fiber distribution, the percentage of tibial nerve myelinated fibers in the diameter ranges of 0-4, 4-6, and 6-10 $\mu \mathrm{m}$ were calculated for each mouse, and the averages per experimental group were determined.

Statistical analysis. The results are expressed as mean \pm SEM. Data were subjected to an equality of variance $F$ test, and then to $\log$ transformation, if necessary, before one-way analysis of variance. Where overall significance $(\mathrm{P}<0.05)$ was attained, individual between group comparisons for multiple groups were made using the Student-Newman-Keuls multiple range test. When between-group variance differences could not be normalized by log transformation (datasets for body weights and plasma glucose), the data were analyzed by the nonparametric Kruskal-Wallis one-way analysis of variance, followed by the Bonferroni/Dunn test for multiple comparisons. Significance was defined at $\mathrm{P}<0.05$.

\section{Results}

Both initial (prior to treatment) and final body weights were lower in Akita mice compared with non-diabetic controls (Table I). A 4-week GPI-15427 treatment did not affect weight gain in either control or Akita mice. Initial non-fasting and fasting blood glucose concentrations were dramatically increased in Akita mice compared with non-diabetic controls. GPI-15427 did not affect non-fasting or fasting blood glucose concentrations in either non-diabetic or Akita mice.

MNCV was not statistically different between 16-week-old control and Akita mice (Table II). Twenty-week-old Akita mice displayed $19.1 \%$ MNCV deficit, and this reduction was essentially prevented by GPI-15427 treatment. SNCV was reduced by 19.6 and $19 \%$, respectively, in 16- and 20 -week-old Akita mice compared with the corresponding non-diabetic groups. PARP inhibitor treatment alleviated the SNCV deficit in Akita mice, without affecting this variable in non-diabetic controls.

The sensitivities to noxious thermal, mechanical, and tactile stimuli were abnormal in both 16- and 20-week-old Akita mice (Table III). In particular, both 16- and 20-week-old Akita mice displayed thermal hypoalgesia which was alleviated, but not completely corrected, by GPI-15427 treatment. They also 
Table III. Indices of small sensory nerve fiber function in non-diabetic and diabetic Akita mice maintained with or without GPI15427 treatment.

\begin{tabular}{|c|c|c|c|c|}
\hline Variables & Control & Control + GPI & Akita & Akita + GPI \\
\hline \multicolumn{5}{|l|}{ 16-week time point (prior to treatment) } \\
\hline Paw withdrawal latency, sec & $10.1 \pm 0.8$ & & $17.3 \pm 1.5^{\mathrm{b}}$ & \\
\hline Mechanical withdrawal threshold, $g$ & $106.9 \pm 3.2$ & & $161 \pm 7.6^{\mathrm{b}}$ & \\
\hline Tactile response threshold, $\mathrm{g}$ & $2.2 \pm 0.2$ & & $1.1 \pm 0.1^{\mathrm{b}}$ & \\
\hline \multicolumn{5}{|l|}{ 20-week time point (final measurements) } \\
\hline Paw withdrawal latency, sec & $10.7 \pm 0.7$ & $10.6 \pm 0.4$ & $18.2 \pm 1^{\mathrm{b}}$ & $12.8 \pm 0.6^{\mathrm{a}, \mathrm{c}}$ \\
\hline Mechanical withdrawal threshold, g & $124.8 \pm 5.1$ & $116.7 \pm 5.8$ & $170.3 \pm 5.6^{\mathrm{b}}$ & $126 \pm 7.7^{\mathrm{c}}$ \\
\hline Tactile response threshold, $\mathrm{g}$ & $1.9 \pm 0.2$ & $1.9 \pm 0.3$ & $0.7 \pm 0.03^{\mathrm{b}}$ & $1.5 \pm 0.1^{\mathrm{c}}$ \\
\hline
\end{tabular}

Data are expressed as mean \pm SEM, $n=6-10$ /group. ${ }^{a} \mathrm{P}<0.05$ and ${ }^{\mathrm{b}} \mathrm{P}<0.01$ vs. non-diabetic controls; ${ }^{\mathrm{c}} \mathrm{P}<0.01$ vs. untreated diabetic Akita mice. GPI, GPI-15427.
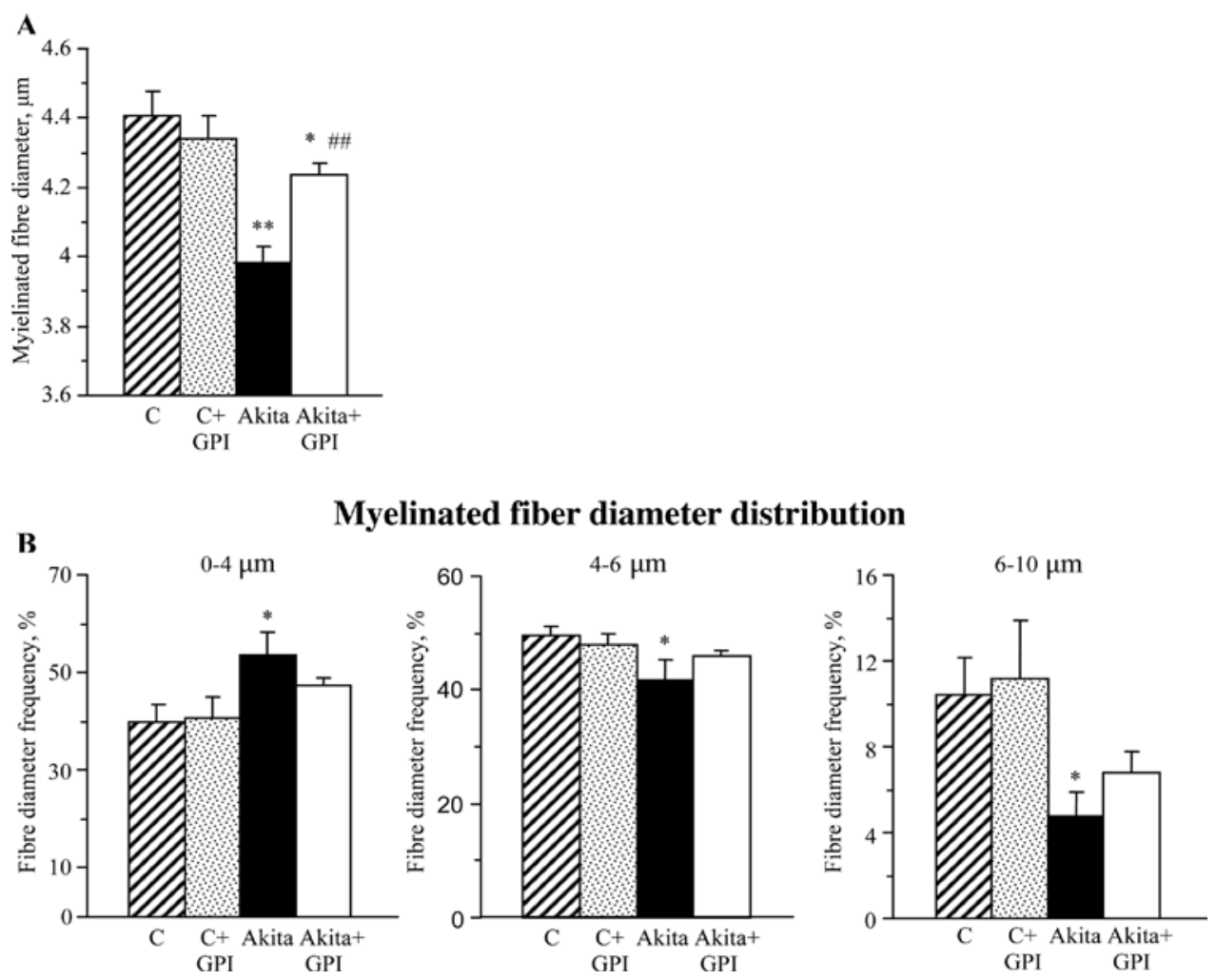

Figure 1. Distal tibial nerve myelinated fiber diameter $(\mu \mathrm{m})(\mathrm{A})$ and distal tibial nerve myelinated fiber diameter distribution (\%) (B), in 20-week-old control and Akita mice maintained with or without GPI-15427 treatment. C, control; GPI, GPI-15427. Mean \pm SEM, $n=8,{ }^{*} \mathrm{P}<0.05$ and ${ }^{* *} \mathrm{P}<0.01$ vs. controls; ${ }^{* \#} \mathrm{P}<0.01$ vs. untreated diabetic Akita mice.

developed mechanical hypoalgesia and tactile allodynia, and both disorders appeared amenable to a PARP inhibitor treatment as reflected by the lack of statistically significant differences in these two variables between the GPI-15427-treated Akita and the non-diabetic control groups. A PARP inhibitor treatment did not affect mechanical withdrawal or tactile response thresholds in non-diabetic mice.

Twenty-week-old Akita mice manifested a 9.7\% reduction in average diameter of distal tibial nerve myelinated fibers indicative of the development of axonal atrophy (Fig. 1A). The analysis of myelinated fiber diameter distribution revealed a pattern typical for DPN, with the loss of large (by 54.6\%) and even medium (by 15.8\%) axons (Fig. 1B). GPI-15427 treatment did not affect average myelinated fiber diameter or diameter distribution in non-diabetic mice, but counteracted axonal atrophy in Akita mice. This neuroprotective effect of PARP inhibition is reflected in the increased average myelinated fiber diameter as well as a shift in the diameter distribution towards the pattern, observed in the non-diabetic group.

Twenty-week-old Akita mice displayed increased p38 MAPK phosphorylation in the peripheral nerve, whereas total p38 MAPK expression was not different from the non-diabetic 
A

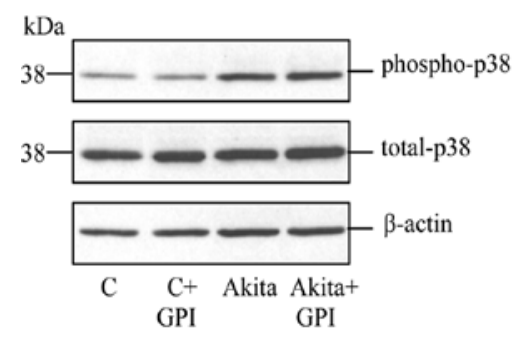

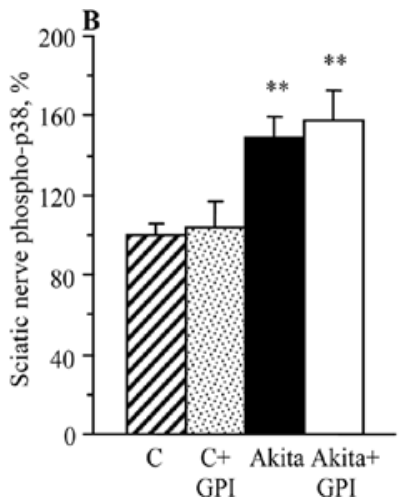

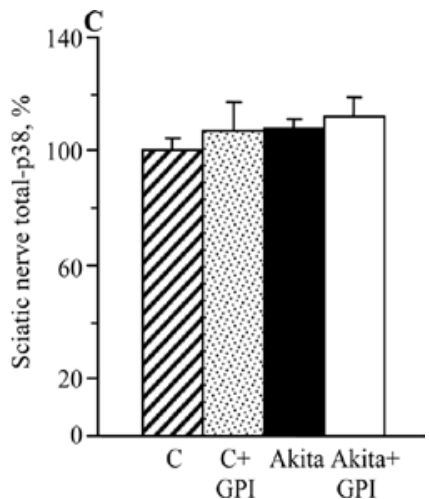

Figure 2. Representative Western blot analysis (A) and contents (\% of control) (B and C) of sciatic nerve phosphorylated and total p38 MAPK in 20-week-old control and diabetic Akita mice maintained with or without GPI-15427 treatment. C, control; GPI, GPI-15427. Mean \pm SEM, $n=8,{ }^{* * *} \mathrm{P}<0.01$ vs. controls.
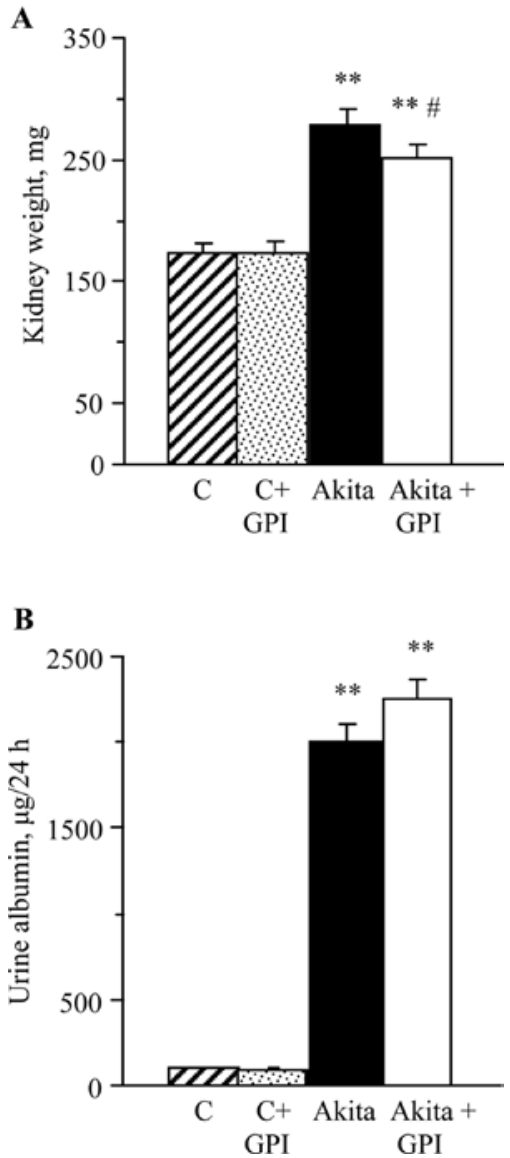

Figure 3. Kidney weights (A) and urinary albumin excretion (B) in control and diabetic Akita mice maintained with or without GPI-15427 treatment. C, control; GPI, GPI-15427. Mean \pm SEM, $n=8,{ }^{* *} \mathrm{P}<0.01$ vs. controls; ${ }^{\#} \mathrm{P}<0.05$ vs. untreated diabetic Akita mice.

controls (Fig. 2). GPI-15427 treatment did not affect total or phosphorylated p38 MAPK expression in either non-diabetic or Akita mice.

Twenty-week-old Akita mice displayed kidney enlargement (Fig. 3A) and dramatic albuminuria (Fig. 3B). GPI-15427 treatment alleviated kidney hypertrophy in Akita mice, without affecting this variable in non-diabetic controls. PARP inhibition did not affect urinary albumin excretion in either non-diabetic or Akita mice.

\section{Discussion}

The results discussed herein indicate that Akita mice develop robust functional and morphological changes characteristic for Type 1 DPN. PARP inhibition counteracted diabetesassociated MNCV and SNCV deficits, thermal hypoalgesia, tactile allodynia, as well as axonal atrophy of distal tibial nerve myelinated fibers, by a mechanism unrelated to alleviation of hyperglycemia. The effects of GPI-15427 on DPN were not mediated through p38 MAPK. A PARP inhibitor treatment was associated with prevention of kidney hypertrophy, but not reduction of albuminuria, in Akita mice.

Identification of suitable rodent models remains an important area of diabetes complication-related research. In the last ten years, DPN and DN have extensively been characterized in animal models of Type 2 diabetes, including Zucker diabetic fatty rats (26-28), and leptin-(ob/ob, 29) and leptin-receptor $(d b / d b, 30)$-deficient diabetic mice. In contrast, STZ-diabetic rat and mouse remain the only models suitable for studying Type 1 DPN, because non-obese diabetic (NOD) mice develop 'brittle diabetes', with unpredictable time of development and exceptionally high mortality, and type 1 bio-breeding Worcester $(\mathrm{BB} /$ Wor) rats require insulin treatment, which interferes with multiple indices of DPN $(31,32)$. Our findings are the first to demonstrate that Akita mouse develops robust nerve conduction slowing, small sensory nerve fiber dysfunction, and axonal atrophy of large myelinated fibers, and, can therefore be used as an alternative to a 'chemical' model of DPN. Note, that several studies suggest that Akita mice also develop a robust diabetic autonomic neuropathy. In particular, diabetic Akita mice manifest impaired corpus cavernosum nitrergic nerve and sinusoidal endothelium function (33). Dystrophic changes have been noted for superior mesenteric and celiac ganglia (34). A further investigation provided evidence for cardiac parasympathetic dysfunction (35). The presence of diabetic autonomic neuropathy in this model is not surprising, considering that diabetic Akita mice develop severe hyperglycemia, which has been identified as one of the major causes of this devastating complication in both experimental and clinical studies (36).

The present study supports an important role for PARP activation in the pathogenesis of DPN previously identified in STZ-diabetic rats and mice (9-11). A PARP inhibitor treatment 
prevented MNCV deficit, and alleviated SNCV deficit, thermal hypoalgesia, and tactile allodynia. Importantly, PARP activation also counteracted diabetes-induced reduction in myelinated fiber diameter and the loss of large axons, a phenomenon typical for human subjects with advanced DPN. Together with the previous studies of our group (9-11) and others (37) obtained in STZ-diabetic rodents, the present experiments provide a strong preclinical proof-of-concept data justifying the clinical neuropathy trials for this class of agents.

PARP activation is known to lead to aberrant transcriptional regulation and gene expression, $\mathrm{NAD}^{+}$depletion, profound metabolic changes, energy failure, impaired ion channel function, inflammation, and oxidative stress $(5,38-40)$. One study also suggested that PARP activation affects MAPK signaling (41). An activation of JNK and increases in total levels of p38 and JNK have been found in the sural nerve of type I and II diabetic patients (42). Furthermore, increased p38 MAPK phosphorylation has been implicated in multiple changes characteristic for experimental DPN $(43,44)$. In the present study, increased p38 phosphorylation was clearly present in the sciatic nerve of Akita mice compared with non-diabetic controls. A PARP inhibitor treatment did not reduce diabetes-associated $\mathrm{p} 38$ MAPK phosphorylation which suggest that PARP activation and p38 MAPK activation are two independent processes in the pathogenesis of DPN. The link, if any, between PARP activation and phosphorylation of other MAPKs in tissue-sites for DPN still remains to be explored.

It is generally accepted that the Akita mouse, at least, the one on the C57Bl6/J background, is not a good model for studying diabetes-associated kidney disease (21). In the present study, however, Akita mice clearly manifested albuminuria and kidney hypertrophy. Note, that whereas renal enlargement appeared partially amenable to GPI-15427 treatment, urinary albumin excretion was not different from the one in the untreated diabetic mice. This finding is not consistent with the previous observations in STZ-diabetic rats and mice $(14,15)$ as well as leptin-deficient $d b / d b$ mice (16), all of which suggest a beneficial effect of PARP inhibition or PARP-1 gene deficiency on this major indicator of diabetic kidney disease. This apparent discrepancy is likely related to the fact that whereas the afore-mentioned previous studies used a prevention paradigm, the current experiments were conducted using an intervention design, with the treatment initiated about 10 weeks after development of overt diabetes. It is also possible that a much longer ( $>4$ weeks) treatment is needed to achieve alleviation of albuminuria in the Akita mouse, a model with exceptionally severe hyperglycemia, which is a generally accepted causative factor of DN (45).

In conclusion, the findings support the important role for PARP activation in peripheral neuropathy and kidney hypertrophy associated with Type 1 diabetes, and provide rationale for the development and further studies of PARP inhibitors, for the prevention and treatment of these complications.

\section{Acknowledgements}

The study was supported by the National Institutes of Health Grants RO1DK074517, RO1DK077141, and RO1DK081147 (all to I.G.O), and the Intramural Research Program of the
National Institutes of Health/National Institute of Alcohol Abuse and Alcoholism (to P.P.).

\section{References}

1. Boulton AJ: The diabetic foot: grand overview, epidemiology and pathogenesis. Diabetes Metab Res Rev 24 (Suppl 1): S3-S6, 2008.

2. Nelson RG, Knowler WC, Pettitt DJ and Bennett PH: Kidney diseases in diabetes. In: Diabetes in America. 2nd edition. National Diabetes Data Group, National Institutes of Diabetes and Digestive and Kidney Diseases (eds). NIH Publication no. 95-1468. Bethesda, Maryland, pp349-385, 1995.

3. Hotta N, Akanuma Y, Kawamori R, et al: Long-term clinical effects of epalrestat, an aldose reductase inhibitor, on diabetic peripheral neuropathy: the 3-year, multicenter, comparative Aldose Reductase Inhibitor-Diabetes Complications Trial. Diabetes Care 29: 1538-1544, 2006.

4. Ziegler D, Ametov A, Barinov A, et al: Oral treatment with alpha-lipoic acid improves symptomatic diabetic polyneuropathy: the SYDNEY 2 trial. Diabetes Care 29: 2365-2370, 2006.

5. Soriano GF, Virag L, Jagtap P, et al: Diabetic endothelial dysfunction: the role of poly(ADP-ribose) polymerase activation. Nat Med 7: 108-113, 2001.

6. Pacher P, Liaudet L, Soriano FG, Mabley JG, Szabó E and Szabó C: The role of poly (ADP-ribose) polymerase activation in the development of myocardial and endothelial dysfunction in diabetes. Diabetes 51: 514-521, 2002.

7. Zheng L, Szabó C and Kern TS: Poly(ADP-ribose) polymerase is involved in the development of diabetic retinopathy via regulation of nuclear factor-kappaB. Diabetes 53: 2960-2967, 2004.

8. Drel VR, Xu W, Zhang J, et al: Poly(ADP-ribose) polymerase inhibition counteracts cataract formation and early retinal changes in streptozotocin-diabetic rats. Invest Ophthalmol Vis Sci 50: 1778-1790, 2009

9. Obrosova IG, Li F, Abatan OI, et al: Role of poly(ADP-ribose) polymerase activation in diabetic neuropathy. Diabetes 53: 711-720, 2004.

10. Ilnytska O, Lyzogubov VV, Stevens MJ, et al: Poly(ADP-ribose) polymerase inhibition alleviates experimental diabetic sensory neuropathy. Diabetes 55: 1686-1694, 2006.

11. Obrosova IG, Xu W, Lyzogubov VV, et al: PARP inhibition or gene deficiency counteracts intraepidermal nerve fiber loss and neuropathic pain in advanced diabetic neuropathy. Free Radic Biol Med 44: 972-981, 2008.

12. Drel VR, Lupachyk S, Shevalye H, et al: New therapeutic and biomarker discovery for peripheral diabetic neuropathy: PARP inhibitor, nitrotyrosine, and tumor necrosis factor- $\{$ alpha $\}$. Endocrinology 151: 2547-2555, 2010.

13. Szabo C, Biser A, Benko R, Bottinger E and Susztak K: Poly(ADPribose) polymerase inhibitors ameliorate nephropathy of type 2 diabetic Leprdb/db mice. Diabetes 55: 3004-3012, 2006.

14. Drel VR, Xu W, Zhang J, Pavlov IA, Shevalye H, Slusher B and Obrosova IG: Poly(Adenosine 5'-diphosphate-ribose) polymerase inhibition counteracts multiple manifestations of experimental type 1 diabetic nephropathy. Endocrinology 150: 5273-5283, 2009.

15. Shevalye H, Stavniichuk R, Xu W, et al: Poly(ADP-ribose) polymerase (PARP) inhibition counteracts multiple manifestations of kidney disease in long-term streptozotocin-diabetic rat model. Biochem Pharmacol 79: 1007-1014, 2010.

16. Shevalye H, Maksimchyk Y, Watcho P and Obrosova IG: Poly(ADPribose) polymerase-1 (PARP-1) gene deficiency alleviates diabetic kidney disease. Biochim Biophys Acta 1802: 1020-1027, 2010.

17. Fong PC, Boss DS, Yap TA, et al: Inhibition of poly(ADP-ribose) polymerase in tumors from BRCA mutation carriers. $N$ Engl $\mathbf{J}$ Med 361: 123-134, 2009.

18. Weston VJ, Oldreive CE, Skowronska A, et al: The PARP inhibitor olaparib induces significant killing of ATM-deficient lymphoid tumor cells in vitro and in vivo. Blood 116: 4578-4587, 2010.

19. Penning TD: Small-molecule PARP modulators-current status and future therapeutic potential. Curr Opin Drug Discov Devel 13: 577-586, 2010.

20. Yoshioka M, Kayo T, Ikeda T and Koizumi A: A novel locus, Mody4, distal to D7Mit189 on chromosome 7 determines earlyonset NIDDM in nonobese C57BL/6 (Akita) mutant mice. Diabetes 46: 887-894, 1997. 
21. Breyer MD, Böttinger E, Brosius FC III, Coffman TM, Harris RC, Heilig CW and Sharma K; AMDCC: Mouse models of diabetic nephropathy. J Am Soc Nephrol 16: 27-45, 2005.

22. Obrosova IG, Ilnytska O, Lyzogubov VV, Pavlov IA, Mashtalir N, Nadler JL and Drel VR: High-fat diet induced neuropathy of pre-diabetes and obesity: effects of 'healthy' diet and aldose reductase inhibition. Diabetes 56: 2598-2608, 2007.

23. Stavniichuk R, Drel VR, Shevalye H, Vareniuk I, Stevens MJ, Nadler JL and Obrosova IG: Role of 12/15-lipoxygenase in nitrosative stress and peripheral prediabetic and diabetic neuropathies. Free Radic Biol Med 49: 1036-1045, 2010.

24. Yagihashi S, Yamagishi SI, Wada Ri R, Baba M, Hohman TC Yabe-Nishimura $\mathrm{C}$ and Kokai Y: Neuropathy in diabetic mice overexpressing human aldose reductase and effects of aldose reductase inhibitor. Brain 124: 2448-2458, 2001

25. Ho EC, Lam KS, Chen YS, et al: Aldose reductase-deficient mice are protected from delayed motor nerve conduction velocity, increased c-Jun NH2-terminal kinase activation, depletion of reduced glutathione, increased superoxide accumulation, and DNA damage. Diabetes 55: 1946-1953, 2006.

26. Li F, Abatan OI, Kim H, Burnett D, Larkin D, Obrosova IG and Stevens MJ: Taurine reverses neurological and neurovascular deficits in Zucker diabetic fatty rats. Neurobiol Dis 22: 669-676, 2006.

27. Oltman CL, Davidson EP, Coppey LJ, Kleinschmidt TL, Lund DD, Adebara ET and Yorek MA: Vascular and neural dysfunction in Zucker diabetic fatty rats: a difficult condition to reverse. Diabetes Obes Metab 10: 64-74, 2008

28. Brussee V, Guo G, Dong Y, et al: Distal degenerative sensory neuropathy in a long-term type 2 diabetes rat model. Diabetes 57 : 1664-1673, 2008.

29. Drel VR, Mashtalir N, Ilnytska O, Shin J, Li F, Lyzogubov VV and Obrosova IG: The leptin-deficient (ob/ob) mouse: a new animal model of peripheral neuropathy of type 2 diabetes and obesity. Diabetes 55: 3335-3343, 2006.

30. Muller KA, Ryals JM, Feldman EL and Wright DE: Abnormal muscle spindle innervation and large-fiber neuropathy in diabetic mice. Diabetes 57: 1693-1701, 2008.

31. Toth C, Brussee V and Zochodne DW: Remote neurotrophic support of epidermal nerve fibres in experimental diabetes. Diabetologia 46: 1081-1088, 2006.

32. Francis G, Martinez J, Liu W, et al: Intranasal insulin ameliorates experimental diabetic neuropathy. Diabetes 58: 934-945, 2009.

33. Jia L, Xie D, Wang X, Liu Y, Li Y, Zhang X: Reduced vasoreactivity in corpus cavernosum of Akita mouse. J Androl 31 $547-551,2010$.
34. Schmidt RE, Green KG, Snipes LL and Feng D: Neurite dystrophy and neuronopathy in Akita (Ins2 $2^{\text {Akita }}$ ) diabetic mouse. Exp Neurol 216: 207-218, 2009.

35. Park HJ, Zhang Y, Du C, et al: Role of SREBP-1 in the development of parasympathetic dysfunction in the hearts of type 1 diabetic Akita mice. Circ Res 105: 287-294, 2009.

36. Tesfaye S, Boulton AJ, Dyck PJ, et al: Diabetic neuropathies: update on definitions, diagnostic criteria, estimation of severity, and treatments. Diabetes Care 33: 2285-2293, 2010.

37. Gibson TM, Cotter MA and Cameron NE: Effects of poly(ADPribose) polymerase inhibition on dysfunction of non-adrenergic non-cholinergic neurotransmission in gastric fundus in diabetic rats. Nitric Oxide 15: 344-350, 2006.

38. Ha HC, Hester LD and Snyder SH: Poly(ADP-ribose) polymerase-1 dependence of stress-induced transcription factors and associated gene expression in glia. Proc Natl Acad Sci USA 99: 3270-3275, 2002.

39. Jagtap P and Szabo C: Poly(ADP-ribose) polymerase and the therapeutic effects of its inhibitors. Nat Rev Drug Discov 4: 421-440, 2005

40. Lupachyk S, Shevalye H, Maksimchyk Y, Drel VR and Obrosova IG: PARP inhibition alleviates diabetes-induced systemic oxidative stress and neural tissue 4-hydroxynonenal adduct accumulation: correlation with peripheral nerve function. Free Radic Biol Med: Feb 23, 2011 (Epub ahead of print).

41. Veres B, Radnai B, Gallyas F Jr, Varbiro G, Berente Z, Osz E and Sumegi B: Regulation of kinase cascades and transcription factors by a poly(ADP-ribose) polymerase-1 inhibitor, 4-hydroxyquinazoline, in lipopolysaccharide-induced inflammation in mice. J Pharmacol Exp Ther 310: 247-255, 2004

42. Purves T, Middlemas A, Agthong S, Jude EB, Boulton AJ, Fernyhough $\mathrm{P}$ and Tomlinson DR: A role for mitogen-activated protein kinases in the etiology of diabetic neuropathy. FASEB J 15: 2508-2514, 2001

43. Price SA, Agthong S, Middlemas AB and Tomlinson DR: Mitogen-activated protein kinase p38 mediates reduced nerve conduction velocity in experimental diabetic neuropathy: interactions with aldose reductase. Diabetes 53: 1851-1856, 2004.

44. Price SA, Gardiner NJ, Duran-Jimenez B, Zeef LA, Obrosova IG and Tomlinson DR: Thioredoxin interacting protein is increased in sensory neurons in experimental diabetes. Brain Res 1116: 206-214, 2006.

45. Mattila TK and de Boer A: Influence of intensive versus conventional glucose control on microvascular and macrovascular complications in type 1 and 2 diabetes mellitus. Drugs 70: 2229-2245, 2010. 